\title{
REPRESENTAGIONES DEL GENIO DEL AÑO EN MOSAICOS HISPANOROMANOS
}

\author{
D. FERNANDEZ-GALIANO \\ O. Diaz TRujillo \\ B. Consuegra Cano
}

El motivo de este trabajo es presentar dos mosaicos descubiertos desde antiguo que, hasta el momento, no han sido debidamente interpretados. Nos estamos refiriendo, en primer lugar, a un mosaico proveniente de Aranjuez, actualmente en el Museo Arqueológico Nacional, de dimensiones aproximadamente cuadradas, de $110 \times 109 \mathrm{cms}$. en su parte conservada, en cuyo centro se representa un busto masculino cubierto parcialmente por una túnica que deja al descubierto su hombro derecho; sobre el izquierdo, que aparece totalmente cubierto por el manto, apoya un cuerno de la abundancia, apreciándose varios frutos en su interior, el mayor de ellos una granada. Una serpiente se enrosca al mismo y aparece en la parte superior del cuerno (figura 1).

La cabeza del personaje es muy voluminosa y se halla ornada de gran cantidad de frutos, hojas y otros elementos vegetales. Parte del cabello cae a la derecha sobre el hombro desnudo del personaje, quien porta un collar con pequeñas teselas amarillas simulando colgantes.

La dificultad para la correcta valoración de este pavimento se centra en dos puntos directamente relacionados: el total desconocimiento de las circunstancias de su hallazgo y las dificultades de identificación del personaje representado en el mosaico.

Enfrentándonos al primero de estos aspectos, tenemos que señalar el expediente de entrada en el Museo indica simplemente una procedencia: Aranjuez, unido a su nombre romano y a la fecha de 1894. La identificación de "Ara Jovis" con que aparece en los inventarios parece querer vincular esta obra a su probable procedencia, apuntando a su pasado romano.

La existencia de una corte ilustrada en el s. XVIII en Aranjuez ha motivado dudas sobre la posibilidad de que este mosaico se trate de una falsificación o, más bien, de "un estudio de la técnica del mosaico» (Balil Illana, 1976, 9). Ahora bien: junto a esta inseguridad tenemos, por una parte, el dato de ciertos autores de la primera mitad del siglo, que indican el descubrimiento de Aranjuez de pavimentos romanos, junto con lápidas y "restos de un tejar a dos kilómetros al norte de la ciudad" (Fuido Rodríguez, 1934, 66). 
Este testimonio, que podría apoyar la autenticidad del pavimento, se ve reforzado por las características del documento: es evidente que una buena parte de la superficie ha sufrido restauración (figura 2), pero no es menos evidente que ciertas partes del mismo son antiguas. Tampoco hay que olvidar que la existencia de dicha corte en Aranjuez pudo haber apoyado la realización de excavaciones arqueológicas, o simplemente, haber valorado, importándolos de otros lugares, restos arqueológicos diversos: en los pavimentos de la Casa del Labrador se hallan insertados mosaicos originales, con temas de peces, procedentes del "Circo Romano de Mérida", noticia que parece ignorar toda publicación hasta la fecha.

La restauración afecta, a simple vista a la parte inferior del manto rojo, cuyas teselas intentan mantener la continuidad de los materiales antiguos, aún siendo claramente discernibles; al collar que porta el personaje, alguna de cuyas teselas, las vidriadas, son auténticas; a la serpiente en su parte superior y, finalmente, a la nariz y boca del personaje. Es aquí donde radica el problema de la interpretación del mismo: la nariz recta y el correcto sombreado, junto con el modelado de los labios muestran una perfección y un estilo más próximo a la pintura neoclásica que a modo de hacer de los musivarios romanos.

La figura, pues, debió haber perdido gran parte de la superficie de la cara, lo que llevó a restaurarla. El hecho de hallarse ante una restauración moderna, debido al desconocimiento del tema motivo de nuestro trabajo en otros mosaicos hispanos, ha inducido a una interpretación errónea de este pavimento: los autores que han citado este mosaico se han referido al personaje representado como Dionisio, (Balil Illana, 1976, 19), Vertumno (Quintero, 1911, 13) o una de las Estaciones, probablemente el Otoño o Flora (Pericot García, 1934, 585).

Así, creemos necesario señalar los datos que tenemos para la correcta interpretación del personaje: una figura con la cabeza profusamente ornada de frutos y elementos vegetales, el hombro derecho desnudo y el izquierdo cubierto por una túnica, con una cornucopia llena de frutos y una serpiente enrollada a la misma.

Suponiendo que el personaje representado sea masculino, tal como hoy lo presenta la restauración, hay que poner en duda su interpretación como una de las Estaciones, que lógicamente habría de ser Primavera u Otoño. En primer lugar, porque los bustos estacionales conocidos son casi siempre femeninos; y, además, porque los atributos que porta no se corresponden con las representaciones conocidas: en caso de tratarse de Primavera, choca la ausencia de flores y de ser Otoño extraña la ausencia de racimos de vid, consustanciales con cada uno de estos tipos de alegorías. Asimismo, la existencia de una serpiente no cuadra bien con estas interpretaciones, ya que este animal no acompaña a las representaciones estacionales. Otro tanto podría afirmarse respecto a las posibles interpretaciones como Vertumno, Flora o Dionisio.

El segundo mosaico motivo de nuestro estudio formaba parte de un pavimento que decoró una de las estancias de la denominada "Casa de los Pájaros» en Itálica, actualmente desaparecido (figura 3).

En el centro de un medallón circular inscrito en un octógono, se representa un busto de un joven cubierto parcialmente por una túnica que deja al descubierto 


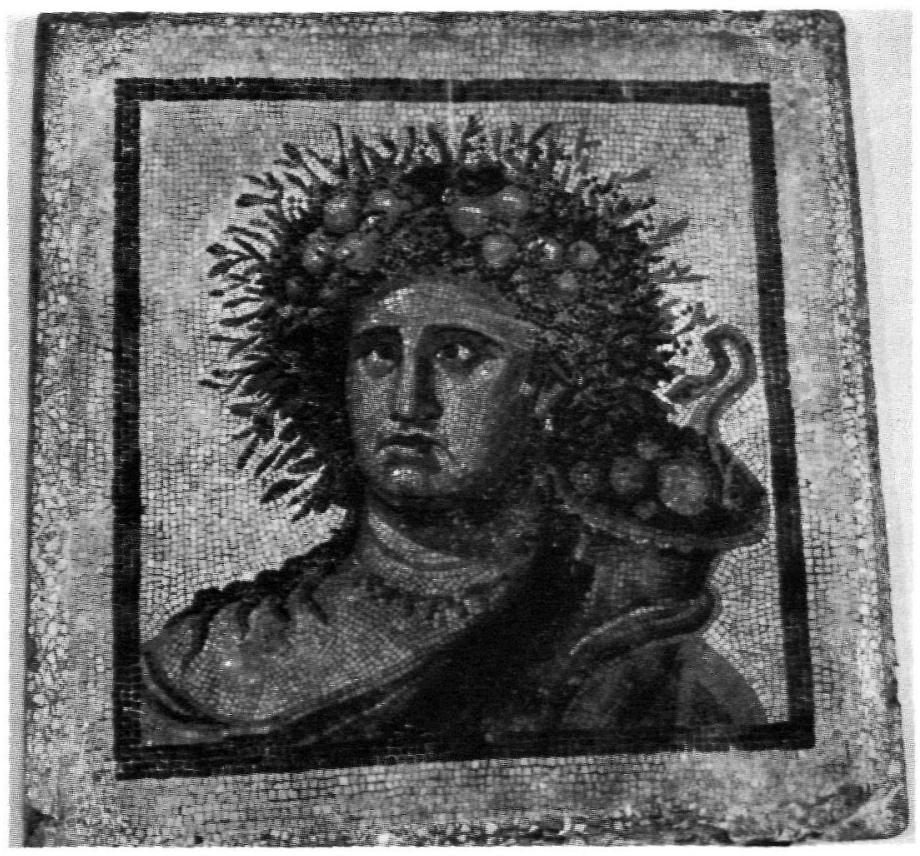

FIG. 1

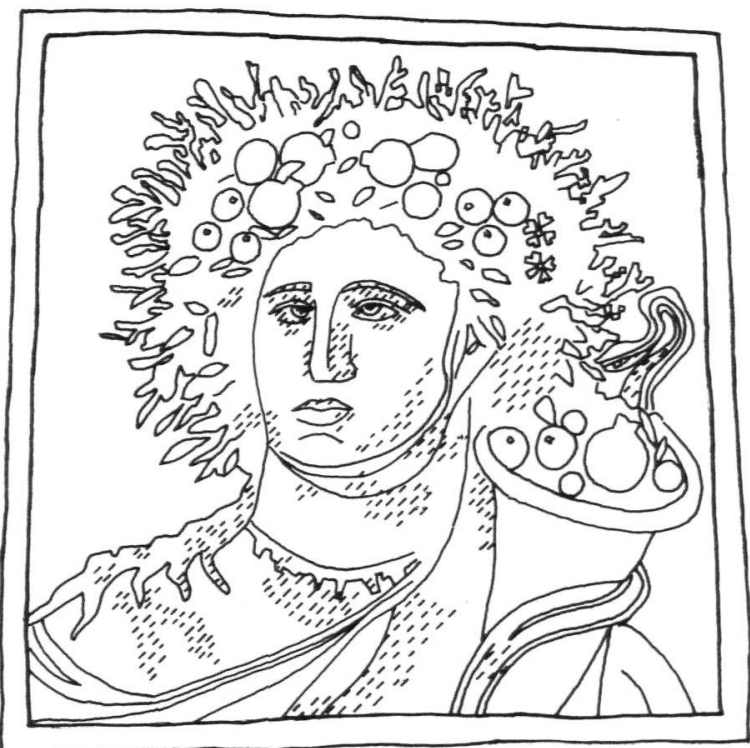

FIG. 2.-Dibujo: C. Ibáñez Ruiz. 
su hombro derecho; una serpiente, que a modo de torques le rodea el cuello, parece salir debajo del ropaje. La cabeza, de cabellos largos, lleva un tocado compuesto por ramas, flores, espigas, manzanas y una granada. En las esquinas aparecen cuatro distintos tipos de aves estacionales.

El pavimento apareció en 1930, y desde el momento de su hallazgo, la figura que se hallaba en su centro fue considerada como "cabeza femenina" (Parlade, 1934, 18) o incluso como un posible busto de Baco; en 1972 fue estudiado por J. M. Luzón, quien interpretó la figura como Tellus, comparándola con imágenes de $\mathrm{Ge}$ en mosaicos de Antioquía (?). En uno de estos mosaicos aparece una imagen femenina con algunos atributos de fertilidad: dos karpoi con sendos cuernos de la abundancia y una serpiente; junto a la figura femenina, la inscripción $\mathrm{H}$. La aparición de la serpiente en estos pavimentos se justifica por tratarse de un animal asociado al mundo subterráneo, símbolo de renovación al cambiar anualmente su piel. A esta identificación con las fuerzas regeneradoras, profundas y misteriosas de la tierra obedece su presencia en los mosaicos de Antioquía e Itálica, independientemente de las figuras a quienes acompaña.

Rechazamos, pues, en nuestro estudio, las interpretaciones propuestas hasta la fecha; la atribución a Tellus, que es la más aproximada a la naturaleza de las figuras representadas, debe ser asimismo descartada por las razones que a continuación exponemos. Partiendo de la base de que son personajes masculinos los representados, nosotros proponemos la identificación como "Genios del Año», estrechamente relacionados con figuras de mosaicos norteafricanos, en forma de hombres jóvenes, imberbes, desnudos, estantes junto a un círculo zodiacal que sostienen en su mano derecha, mientras en la izquierda sujetan un cuerno de la abundancia cargado de frutos. Las imágenes tópicas de especies vegetales adecuadas - rosas, espigas de trigo, racimos de uvas y ramas de olivo- situadas en su torno, evocan las cuatro estaciones. Esta disposición presentan las figuras deĩ mosaico de Hipona (Foucher, 1981-3) y se repite igualmente en los pavimentos de El Haidra, Dougga y Cartago, donde esta figura se rodea de bustos de las cuatro estaciones. Lo mismo cabría decir de otros mosaicos, como los de Isola Sacra y Trinquetaille, en Arles, y hasta cabe la posibilidad de reconocer una representación de este personaje en el mosaico de Fernán Núñez, acompañado de las Cuatro Estaciones (FernándezGaliano 1982, fig. 1 y 4 ).

Una interpretación nueva, como la que proponemos, aplicada por vez primera a figuras de mosaicos de nuestro país, requiere hacer una serie de consideraciones de carácter iconográfico y conceptual para explicar la génesis, evolución y tipología de las imágenes representadas, dado que existe una cierta confusión, incluso entre los arqueólogos e historiadores del arte, a la hora de referirse a las mismas.

Estas figuras de jóvenes sosteniendo un círculo zodiacal y vinculadas a símbolos de abundancia y fertilidad, son imágenes de raíces y significado no demasiado claros, que sufrieron una evolución a lo largo del tiempo; a la dificultad de definir con más o menos precisión los conceptos que las sustentaban se añãde la diversidad formal con que los artistas los plasmaron y los problemas derivados de la evolución que dichas ideas sufrieron a lo largo del tiempo. En el estudio de la mitolo- 


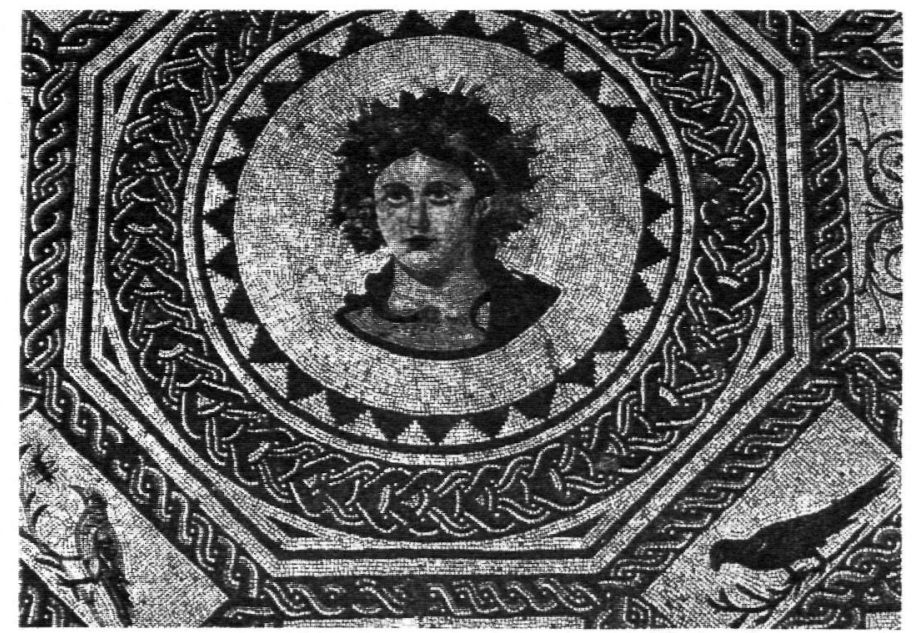

FIG. 3

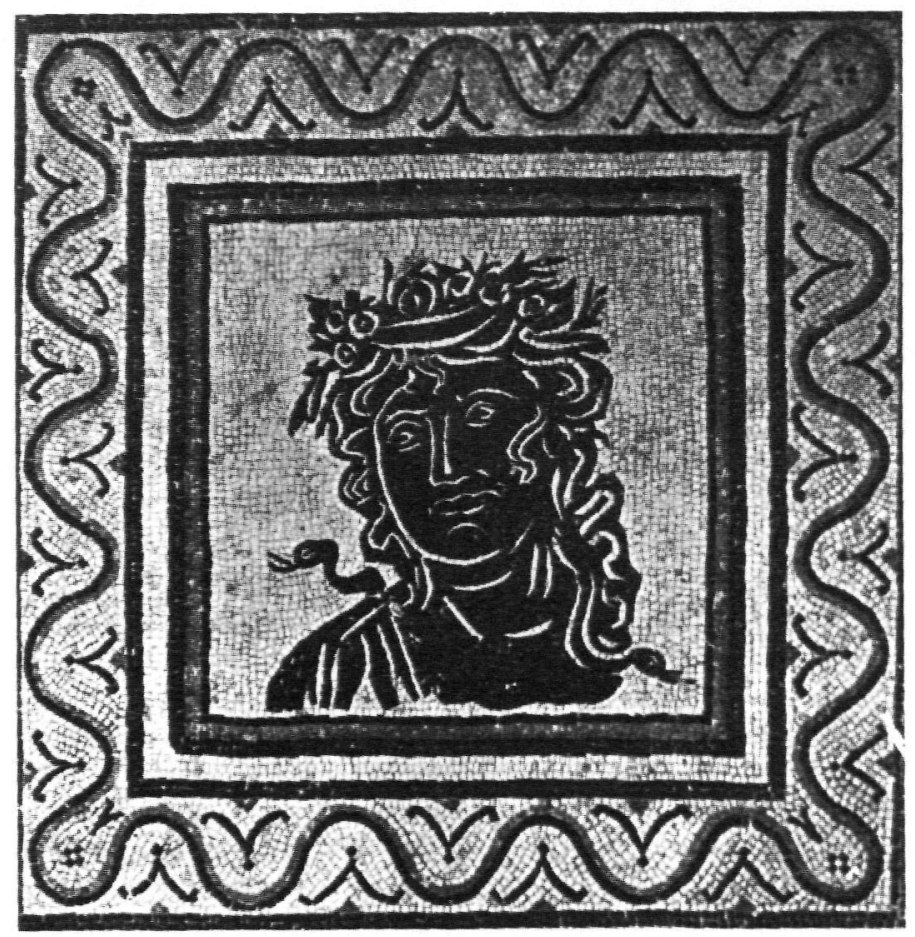

FIG. 4.-Reproducción. R. Lorente. 
gía y de la iconografía mitológica, es fácil deslizarse de conceptos poco concretos a otros más o menos relacionados con ellos; de hecho, la diversidad terminológica con que la bibliografía especializada los ha aludido es claro índice de la confusión que se ha creado en torno a ellos. Aión, Aeternitas, Saeculum Aureum, Genio del Año, son algunos de los nombres con que arqueólogos e historiadores han tratado de definir las figuras a ellos asociadas, aunque no existe unanimidad en la atribución y significado de cada uno de los tipos iconográficos.

Por ello, trataremos de definirlos lo más breve y concisamente posible, a sabiendas de que hemos de incurrir en una cierta simplificación inevitable a la hora de diferenciarlos.

La primera de estas elaboraciones, por su antigüedad, es la de Aion. Para Platón (Timeo 37) significa el tiempo absoluto, por oposición a Cronos, el tiempo en relación a la vida humana.

La palabra griega Aion deriva, al parecer, de una raíz indoeuropea, ai-w, cuyo significado es "eternidad». Sin embargo, la expresión indoeuropea de Eternidad no está, en su origen, ligada al concepto tiempo, sino al de "fuerza vital» traducción literal del términio Aion (Benveniste, 1937, 103 112). El radical ai-w (eternidad) se encuentra tanto en Aion como en la palabra latina juvenis, que en ambos casos sólo indica "lo que está perpetuamente empezando" (Dumezil, 1938, 289-295).

Los tratadistas latinos, estableciendo una relación de equivalencia directa, no dudan en afirmar que Aeternitas es la traducción latina del Aion griego, es decir el tiempo sin principio ni fin.

Por otra parte, en época romana, existe también una forma dinivizada, bajo el nombre de Saeculum, de la personificación del tiempo perdurable y cósmico; este tiempo indefinido se asocia en un momento indeterminado con una serie de connotaciones de tipo benéfico: son los Saecula aurea virgilianos, la edad de oro cargada de bienes. Se ha documentado, incluso, una forma de culto local a Aeculum Frugifer, es decir, el ciclo cósmico que acarrea la fertilidad de los campos.

Dos son las ideas fundamentales, que van a confluir en época romana: una, Aion, de carácter exclusivamente temporal, algo así como la «eterna juventud»; otra, Saeculum el tiempo eterno, que a partir de ciertos momentos será "El tiempo que trae bienes". Estos son los dos conceptos fundamentales que confluyeron en época helenística y romana: veamos ahora su materialización en tipos iconográficos, y su interés para el estudio de los mosaicos objeto de este trabajo.

Las únicas representaciones claras de Aion en la iconografía conocida lo figuran de forma muy diferente: el relieve de Afrodisias lo representa como un anciano barbado, sentado, con la cabeza velada y el cuerpo envuelto en una túnica. Un segundo tipo iconográfico de Aion debió de generarse igualmente en época helenística, aunqué el ejemplo más claro conocido pertenece a época romana tardía: se trata del mosaico de Chabba (Filipópolis), donde aparece un joven desnudo con un círculo zodiacal en su mano: dado que la raiz ai-w significa "fuerza vital" les debió de parecer lógica a los creadores helenísticos su representación como un joven.

Este joven portador del círculo zodiacal se representó en monedas romanas acuñadas con motivo del comienzo del año, a partir de Adriano, en las que se repre- 


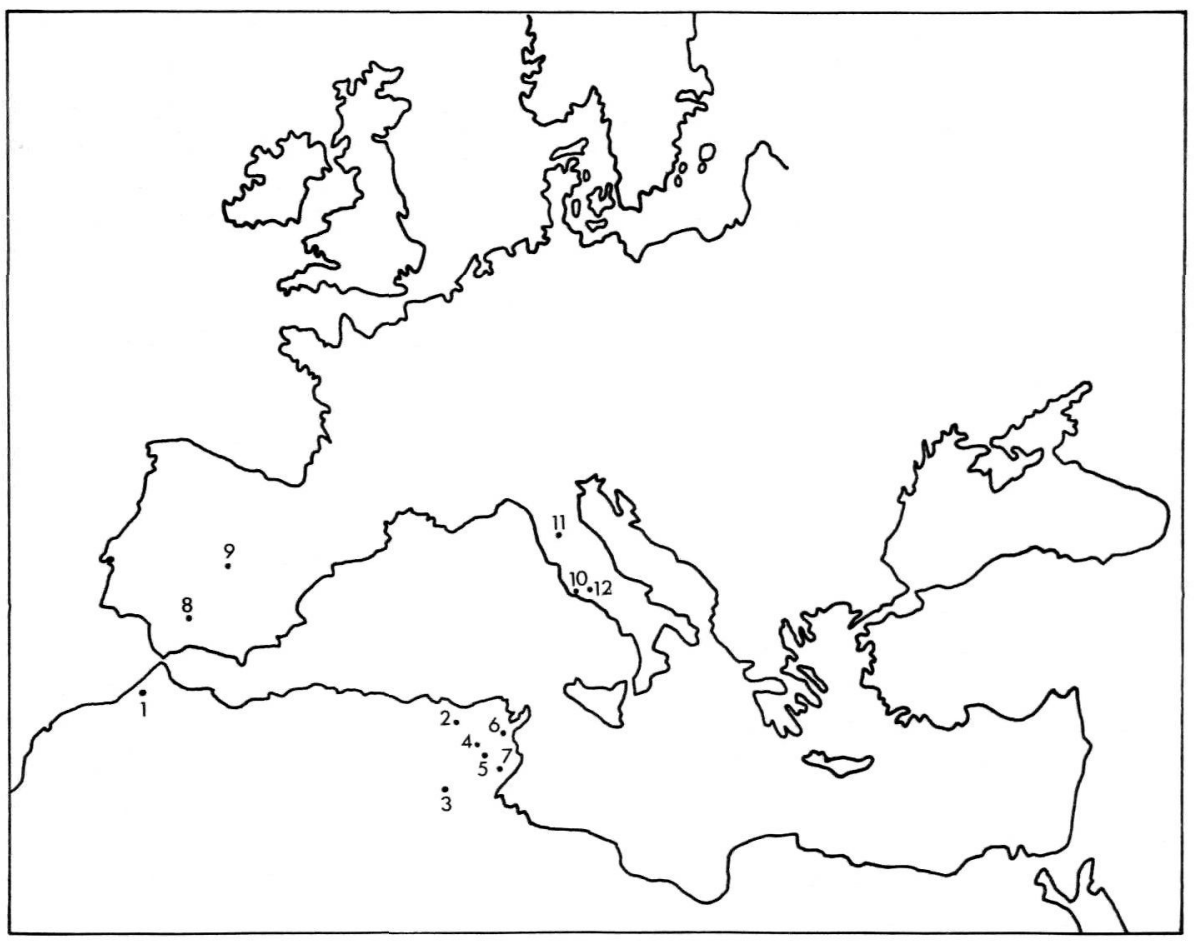

FIG. 5.-Distribución de mosaicos con el tema "Genio del Año".
1. Voluvilis.
2. Hippo Regius.
3. Haïdra.
4. Dougga.
5. Dougga 2 .
6. Cartago.

7. El Ajem.

8. Itálica.

9. Aranjuez.

10. Ostia.

11. Sentinum.

12. Roma.

senta la imagen del joven con el círculo zodiacal junto a las leyendas SAEC(ulum) AVR (eum), la "Edad de Oro» resultado de la permanencia del Imperio, que garantiza la prosperidad al mundo. Esta idea de la Edad de Oro ya contiene implícita la noción de fertilidad y de prosperidad (no consustancial a la figura de Aión), y se trata claramente de la divulgación de la creencia, como instrumento de propaganda política, de la perfección del orden cósmico (Quet, 1984, 104) asegurada por la continuidad del sistema de organización social y política romanas. 
En estas monedas se representa al joven manteniendo el círculo zodiacal, acompañado de una serpiente y símbolos astrales, junto a las leyendas SAEC AVR y AETERNITAS. Desde época de Adriano, y seguramente antes, ya se vincula a este Aion con la fertilidad que propicia el tiempo. Es difícil discernir, en efecto, en que momento debemos dejar de llamar Aion a este joven para llamarle Saeculum Aureum, dado que el añadido de los valores de fertilidad y abundancia se produce paulatinamente. Pero parece adecuado reservar el nombre Aion para dos tipos iconográficos: el viejo velado y barbado, y el joven desnudo junto al círculo zodiacal. Ambos tipos iconográficos representan al tiempo, sin connotaciones de fertilidad.

Parece, además, detectarse una mayor pureza conceptual en las representaciones iconográficas de este Aion joven más vinculadas al helenismo: por ejemplo, en los mosaicos de Sentinum, Filipópolis o Mérida y en la lanx de Parabiado, donde Aion aparece diferenciado como figura no frugífera, junto a las de Tellus y los Karpoi estacionales, éstas sí son sus frutos característicos.

En otros mosaicos, norteafricanos en su mayor parte (Haidra, Cartago, Hipona, etc.) la figura del joven con el círculo zodiacal ya ha tomado en sus manos los mismos signos de la fertilidad y de la abundancia: en estos casos creemos que cabe ya hablar del Genio del Año.

El Genio del Año es la personificación del Año, que según la descripción de Ateneo, aparecía en la procesión de Ateneo Filadelfo: «... este desfile contenía gran número de figuras dionisiacas tales como sátiros, silenos, ménades y una estatua del mismo dios del vino así como la personificación del año Aniautos, que era seguido por las cuatro estaciones. Eniautos es un hombre alto, viste el traje y la máscara de un actor trágico que sostiene la cornucopia (Ateneo, $5198 \mathrm{a}-\mathrm{b}$ ). Este personaje parece el representado en un mosaico de Dougga (Parrish, 1981, 15).

El Genio del Año, de este modo, se nos aparece como un joven con símbolos de fertilidad y abundancia: puede ser el joven desnudo con el círculo zodiacal en una mano y la cornucopia en la otra, de los mosaicos de Cartago o de Hipona: pero también, en un segundo tipo iconográfico, simplemente como un joven en forma de busto con símbolos de fertilidad, renovación y abundancia. A este tipo pertenecen los mosaicos de el Jem, Dougga, el del Museo Nacional Romano, así como el de Itálica y el de Aranjuez estudiados.

\section{Agradecimientos}

Queremos expresar nuestro agradecimiento a Luis Caballero Zoreda y a Antonio Méndez Madariaga, que en todo momento facilitaron nuestro trabajo. 


\section{BIBLIOGRAFIA}

ALFOLDI, A. (1979): Aion in Merida und Aphorodisias, Mainz.

Balil Illana, A. (1978): «Estudios sobre mosaicos romanos, IV». Studia Archaeologica, 39, pág. 9.

BENVENISTE, E. (1937): «Expresión indo-européenne de l'Eternité», Bulletin de la Societé linguistique de París, XXVII, págs. 103-112.

Blanco Freijeiro, A. (1978): Mosaicos Romanos de Itálica (1), Madrid. (1978b).: Mosaicos Romanos de Mérida, Madrid.

BlázQuer MARTINEZ, J. M. (1986): "Cronología mitraica en un mosaico de Augusta Emerita", Archivo Español de Arqueología, 59, págs. 89-100.

DumezIL, G. (1938): "Jeunese, éternité, aube; lingüistique comparée et mythologie comparées indo-européennes", Annales X, págs. 289-301, el'Histoire Economique at Sociale X, n. ${ }^{\circ}$ 52, 1958, 1963: Enciclopedia Dell'Arte Antica Classica e Orientale, vols. I y V, Roma.

FERNÁNDEZ-GALIANO RUIZ, D. (1982): «Nuevas interpretaciones iconográficas sobre mosaicos hispanorromanos" Museos, 1, págs. 17-27. (1984): "El triunfo de Dionisos en mosaicos hispanorromanos", Archivo Español de Arqueología, vol. 57, págs. 97-114.

FOUCHER, L. (1981): "La representation du genie de L'année sur les mosaiques», Mosaique Romaine Tardive, 3-10.

FonT Gratacos, L. (1946): "El tapiz de la catedral de Gerona», Anales del Instituto de Estudios Gerundenses, vol. I, págs. $160,171$.

FUIDO RODRÍGUEZ (1934): Carpetania Romana, Madrid.

Hanfmann, G. M. H. (1951): The Season Sarcophagus in Dumbarton Oaks, Cambridge, Massachussetts.

Lavagne, H. (1981): "Remarques sur l'Aion de la mosaique de Sentum», Mosaique Romaine Tardive, 27-40.

LEvi, D. (1968): “Aion», Hesperia 13, págs. 269-314.

Luzon Nogue, J. M. (1972): "Mosaico de Tellus en Itálica», Habis III, págs. 291-295.

PARLADE, J. (1925-1932): “Excavaciones en Itálica, campañas de 1925 a 1932». Memorias de la Junta Superior de Excavaciones.

PaLOL, P. (1956-57): Une broderie catalane d'époque romaine: la Genéses de Gérone“, Cahiers Archéologiques 8-9, págs. 175-214.

PARRISH, D. (1981): «Annus-Aion in Roman mosaics» Mosaique Romaine Tardive, págs. 11-25. (1984): Season Mosaics of Roman North Africa, Roma.

PAULY-WissoWA, 1918: Real Encyclopadie der Classichen Alter tums Wissenschaft, Suppl. III, págs. 64-68.

Pericot GARCIA, L. (1934): Historia de España, vol. I, Barcelona.

Quet, N. H. (1979): "La mosaique cosmologique de Merida. Propositions de lecture», Coninbriga XVIII, págs. 5-103. (1968): “Aion, á propos d'une libre récent», Revue des Studes Anciennes, págs. 97-107.

QUinTero, P. (1911): «El mosaico de Carácter romano en España», Museum, 1, pág. 13. 